\section{FRI0564 128 PATIENTS WITH SUBACUTE SYMPTOMATIC FRAGILITY VERTEBRAL COMPRESSION FRACTURES: HIGH INCIDENCE OF MORTALITY, FALLING, MONOCLONAL GAMMOPATHY OF UNCERTAIN SIGNIFICANCE AND MYELOMA, PERNICIOUS ANEMIA AND VITAMIN B-12 DEFICIENCY: IS THIS A PROFILE OF AN OSTEOPOROTIC OR AN AGED POPULATION?}

M. Lovy ${ }^{1}$, N. Ben-Shlomo ${ }^{2}$, J. Udkoff ${ }^{3} .{ }^{1}$ Desert Oasis Healthcare, Palm Springs, California, United States; ${ }^{2}$ Ben-Gurion Medical School, Beer Sheva, Israel; ${ }^{3}$ University of California, San Diego Medical School, San Diego, California, United States

Background: Epidemiological studies have identified risk factors for falling and fractures. However there is a paucity of observational studies ${ }^{1,2}$ of patients with symptomatic fragility vertebral compression fractures (VCF). These studies were not done in community based populations and did not evaluate the contribution of falling.

Objectives: To study factors contributing to both osteoporosis and falling in a cohort of community based patients with symptomatic subacute fragilty VCF.

Methods: We saw 128 patients with symptomatic subacute fragility VCF in our community based outpatient fracture clinic over a two year period. We performed a complete history and physical, review of past medical records and radiographs, complete blood count, sedimentation rate, chemistry profile, $\mathrm{TSH}$, urinalysis, vitamin $\mathrm{B}-12, \mathrm{PTH}, 25-\mathrm{OH}$ vitamin $\mathrm{D}$, and serum protein electrophoresis (SPE). We performed testosterone level, methylmalonic acid, antiparietal cell antibody and intrinsic factor antibody in select cases. We recorded diseases including diabetes, COPD, cardiac, neurological for each patient.

Results: There were 92 females aged 45-98 years (mean 77.7), 36 males aged 39-94 years (mean 77.6). Factors contributing to falling included peripheral neuropathy-61, use of sedatives-43, blindness-12, foot drop-6, dementia-3, Parkinson's-3, hyponatremia-2. VCF were precipitated by falls in 94 patients, of which 87 occurred at home. VCF occurred with lifting in 8 patients, bending in 3 , and were spontaneous in 23. Use of steroids was reported in 18 patients and associated with mulitple $(>3)$ fractures $(p<0.0008)$. Blindness $(p=0.022)$ and multiple fractures $(p=0.049)$ were found more often among females. Males were more likely to have peripheral neuropathy $(\mathrm{p}=0.056)$ and 3 or more medical conditions $(P<0.008)$. Age correlated with the number of diseases $(p<0.0001)$. Diagnosis based on laboratory studies included vitamin $D$ insufficiency-29, vitamin D deficiency-12, pernicious anemia-6, vitamin B-12 deficiency-8, monoclonal gammopathy of uncertain significance (MGUS)-10, myeloma-2, hypogonadism12 , and iatrogenic hyperthyroidism-3. Ankylosing spondylitis and lymphoma were diagnosed in one patient each. The average age of those that died was 83.9 years compared to 76.8 of the remaining group $(p=0.033)$.

Conclusions: Conditions that increase with age and are associated with an increased risk of falling and fracture include neurological diseases, visual loss, use of steroids and sedatives, MGUS, myeloma, pernicious anemia and vitamin B-12 and vitamin D deficiencies. These were all common in our cohort with subacute symptomatic fragility VCF. Accordingly we recommend vitamin B-12 levels and SPE in the evaluation of all patients with VCF. These findings support the emphasis on interventions to reduce the risk of falling in the elderly and to recognize and treat these age-related conditions in an attempt to mitigate the risk of VCF.

References:

[1] Nola JM, et al, J Rheumatol 2001;28:2289-22-93.

[2] Dumitrescu B, et al, BMC Musculoskeletal Disorders 2008, 9:109.

Disclosure of Interest: None declared

DOI: 10.1136/annrheumdis-2017-eular.2171

\section{FRI0565 FRAGILITY FRACTURES IN PATIENTS ON DEPO-PROVERA ARE NOT ASSOCIATED WITH USUAL RISK FACTORS FOR FRACTURE}

M. Dey, M. Bukhari. University Hospitals of Morecambe Bay NHS Foundation Trust, Lancaster, United Kingdom

Background: Depo-Provera is one of the most widely-used contraceptives. The side-effects includes loss in bone mineral density (BMD), increasing fracture risk $(1,2)$. It is not known if conventional fracture risk factors impact fracture risk in these patients.

Objectives: We set out to determine if the usual risk factors for fracture are associated with increased risk of fragility fractures in patients exposed to Depo-Provera.

Methods: Patients referred for bone densitometry at a scanner in North West of England were analysed. Femoral and vertebral BMD, height, weight and body mass index (BMI) were recorded, in addition to: age, diagnosis of rheumatoid arthritis, smoking status, alcohol consumption, family history of fractures, history of secondary osteoporosis, corticosteroid use, total average proportion fat, average tissue thickness, fat mass, and lean mass. Patients with exposure to Depo-Provera were selected for analysis. Initially patients with and without a fracture were compared using Chi-squared test and T-test. Logistic models were fitted univariately and adjusted for age to analyse association between traditional risk factors and fracture.

Results: 304 females (103 currently and 201 previously on Depo-Provera) were included. $62(20.4 \%)$ had sustained had least one fragility fracture. There was no significant difference in fracture risk between those currently and previously on Depo-Provera $(p=0.17695 \% \mathrm{Cl}$ ). Decreased left femoral BMD significantly impacted fracture risk $(p=0.03595 \% \mathrm{Cl})$. All other factors investigated did not significantly increase fracture risk in this cohort.(see table below)

\begin{tabular}{lccccc}
\hline Predictor & $\begin{array}{c}\text { All } \\
(\mathrm{n}=304)\end{array}$ & $\begin{array}{c}\text { Patients } \\
\text { with } \\
\text { fracture } \\
(\mathrm{n}=62)\end{array}$ & $\begin{array}{c}\text { Patients } \\
\text { without } \\
\text { fracture } \\
(\mathrm{n}=242)\end{array}$ & -value & $\begin{array}{c}\text { Odds ratio } \\
(95 \% \mathrm{Cl})\end{array}$ \\
\hline Age at scan (years) & 36.7 & 41.5 & 39.2 & 0.083 & $1.028[0.10,1.06]$ \\
Height $(\mathrm{m})$ & 163.2 & 163.3 & 163.2 & 0.924 & $1.002[0.96,1.04]$ \\
Weight $(\mathrm{kg})$ & 73.0 & 76.9 & 72.1 & 0.078 & $1.012[0.10,1.03]$ \\
Femoral BMD (left) $\left(\mathrm{g} / \mathrm{cm}^{2}\right)$ & 0.966 & 0.932 & 0.975 & 0.035 & $0.100[0.01,0.82]$ \\
Femoral BMD (right) $\left(\mathrm{g} / \mathrm{cm}^{2}\right)$ & 0.972 & 0.945 & 0.979 & 0.112 & $0.177[0.02,1.47]$ \\
Lumbar spine BMD $(\mathrm{L} 2)\left(\mathrm{g} / \mathrm{cm}^{2}\right)$ & 1.115 & 1.099 & 1.119 & 0.364 & $0.432[0.07,2.62]$ \\
BMl (kg/m $)$ & 27.4 & 28.8 & 27.0 & 0.068 & $1.037[0.10,1.08]$ \\
Average proportion fat & 0.274 & 0.299 & 0.267 & 0.069 & $9.071[0.86,101.12]$ \\
Average tissue thickness (cm) & 17.6 & 18.3 & 17.5 & 0.080 & $1.076[0.99,1.17]$ \\
Fat mass (g) & 275.2 & 302.7 & 268.1 & 0.053 & $1.002[0.10,1.00]$ \\
Lean mass (g) & 724.8 & 697.3 & 731.9 & 0.053 & $0.998[0.10,1.00]$ \\
Alcohol (no. of patients) & 23 & 8 & 15 & 0.102 & $2.235[0.78,5.96]$ \\
Smoking (no of patients) & 154 & 31 & 123 & 1.000 & $0.968[0.53,1.76]$ \\
Family history (no. of patients) & 77 & 17 & 60 & 0.744 & $1.145[0.57,2.22]$ \\
Rheumatoid arthritis (no. of patients) & 11 & 3 & 8 & 0.702 & $1.485[0.25,6.43]$ \\
Secondary operation (no. of patients) & 48 & 10 & 38 & 1.000 & $1.032[0.43,2.29]$ \\
Corticosteroids (no. of patients) & 67 & 18 & 49 & 0.169 & $1.609[0.80,3.14]$ \\
\hline
\end{tabular}

Conclusions: Our study suggests that fragility fractures in patients taking DepoProvera are not associated with the usual risk factors for fractures. To our knowledge, this is the first study demonstrating fracture risk in such patients to be independent of conventional risk factors. This therefore indicates an as yet unidentified mechanism of increased fracture risk. Study limitations include the small number of fractures and lack of data on length of treatment with Depo-Provera. Further research is needed into the mechanisms by which the drug gives rise to increased fracture risk, independent of other factors.

References:

[1] Contraception. United States; $2011 \mathrm{Nov;84(5):e31-7.}$

[2] Obstet Gynecol. United States; 2008 Oct;112(4):788-99.

Disclosure of Interest: None declared

DOI: 10.1136/annrheumdis-2017-eular.1539

\section{FRI0566 TERIPARATIDE AND ALENDRONATE IMPROVED BONE LOSS AND HYPERALGESIA IN A MOUSE MODEL OF OSTEOPOROSIS}

N. Nagao, H. Wakabayashi, S. Kato, G. Miyamura, Y. Naito, A. Sudo. Department of Orthopaedic Surgery, Mie University Graduate School of Medicine, Mie, Japan, Tsu, Japan

Background: Osteoporosis may cause not only fractures but also chronic back pain in elderly women. Teriparatide (TPTD) and alendronate (ALN) are widely used in clinical for treatment of osteoporosis. Several studies have demonstrated that TPTD and ALN treatments improved skeletal pain in osteoporosis patients. Objectives: We investigated the effect of TPTD and ALN on pain-related behavior in ovariectomized (OVX) mice. And we investigated expression of inflammatory cytokines treated OVX mice.

Methods: 8-week-old female ddY mice were OVX and assigned to 4groups; SHAM-operated mice treated with vehicle (SHAM), OVX mice treated with vehicle (OVX), OVX mice treated with TPTD (TPTD) and OVX mice treated with ALN (ALN). Mice were started treatment immediately after surgery. For 4 weeks, mice were injected subcutaneously with vehicle or $40 \mu \mathrm{g} / \mathrm{kg}$ ALN twice a week or $40 \mu \mathrm{g} / \mathrm{kg}$ TPTD 5 times a week.

The bilateral distal femur metaphyses were analyzed three-dimensionally by $\mu C T$ 4 weeks after surgery (each group; $n=8$ ).

Mechanical sensitivity was tested using von Frey filaments 4 weeks after surgery. To evaluate the $50 \%$ withdrawal threshold, seven von Frey filaments with forces of $0.07,0.16,0.4,0.6,1.0,1.4$ and $2.0 \mathrm{~g}$ were applied to the middle of the plantar surface. Data was collected using the up-down method.

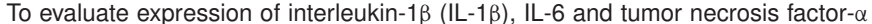
$(\mathrm{TNF}-\alpha)$, mice were anesthetized and the bilateral hindlimb bone excised. We performed quantitative polymerase chain reaction (q-PCR) from hindlimb bone.

Results: $\mu \mathrm{CT}$ analysis of the distal femur metaphysis showed that bone volume/tissue volume (BV/TV) and trabecular number (Tb.N) were significantly less in the OVX group than in the SHAM group, whereas trabecular separation (Tb.Sp) was significantly greater in the OVX group than in the SHAM group. In the TPTD and ALN group, BV/TV and Tb.N were significantly greater than in the OVX group, whereas Tb.Sp was significantly less than in the OVX group. And in the ALN group, BV/TV and Tb.N were significantly greater than in the TPTD group, but Tb.Sp was no significance.

The $50 \%$ withdrawal threshold was significantly lower in the OVX group than in the SHAM group, and it was significantly higher in the TPTD and ALN group than in the OVX group. And the $50 \%$ withdrawal threshold was no significance between the TPTD and ALN group.

The expression levels of TNF- $\alpha$ was increased in the OVX group compared with those in the SHAM group. Other cytokines were not increased significantly in the 